\title{
BMJ
}

\section{Salt intake, stroke, and cardiovascular disease: meta- analysis of prospective studies}

\author{
Pasquale Strazzullo, professor of medicine, ${ }^{1}$ Lanfranco D’Elia, clinical lecturer in medicine, ${ }^{1}$ Ngianga-Bakwin \\ Kandala, principal research fellow in medical statistics, ${ }^{2}$ Francesco P Cappuccio, professor of cardiovascular \\ medicine and epidemiology²
}

\begin{abstract}
${ }^{1}$ Department of Clinical and Experimental Medicine, "Federico

II" University of Naples Medical School, Naples, Italy

${ }^{2}$ University of Warwick, WHO Collaborating Centre for Nutrition, Warwick Medical School, Clinical Sciences Research Institute Coventry CV2 2DX

Correspondence to: P Strazzullo strazzul@unina.it, FP Cappuccio f.p.cappuccio@warwick.ac.uk

Cite this as: BMJ 2009;339:b4567 doi:10.1136/bmj.b4567
\end{abstract}

Objective To assess the relation between the level of

habitual dietary salt intake and blood pressure has been established through experimental, epidemiological, migration, and intervention studies. Most adult populations around the world have average daily salt intakes higher than $6 \mathrm{~g}$, and for many in eastern Europe and Asia higher than $12 \mathrm{~g}$. International recommendations suggest that average population salt intake should be less than 5-6 g per day. Population based intervention studies and randomised controlled clinical trials have shown that it is possible to achieve significant reductions in blood pressure with reduced salt

\section{ABSTRACT} habitual salt intake and stroke or total cardiovascular disease outcome.

Design Systematic review and meta-analysis of prospective studies published 1966-2008.

Data sources Medline (1966-2008), Embase (from 1988), AMED (from 1985), CINAHL (from 1982), Psychinfo (from 1985), and the Cochrane Library.

Review methods For each study, relative risks and $95 \%$ confidence intervals were extracted and pooled with a random effect model, weighting for the inverse of the variance. Heterogeneity, publication bias, subgroup, and meta-regression analyses were performed. Criteria for inclusion were prospective adult population study, assessment of salt intake as baseline exposure, assessment of either stroke or total cardiovascular disease as outcome, follow-up of at least three years, indication of number of participants exposed and number of events across different salt intake categories.

Results There were 19 independent cohort samples from 13 studies, with 177025 participants (follow-up 3.

5-19 years) and over 11000 vascular events. Higher salt intake was associated with greater risk of stroke (pooled relative risk $1.23,95 \%$ confidence interval 1.06 to 1.43 ; $\mathrm{P}=0.007)$ and cardiovascular disease $(1.14,0.99$ to 1.32 ; $\mathrm{P}=0.07$ ), with no significant evidence of publication bias. For cardiovascular disease, sensitivity analysis showed that the exclusion of a single study led to a pooled estimate of 1.17 (1.02 to $1.34 ; \mathrm{P}=0.02)$. The associations observed were greater the larger the difference in sodium intake and the longer the follow-up.

Conclusions High salt intake is associated with significantly increased risk of stroke and total cardiovascular disease. Because of imprecision in measurement of salt intake, these effect sizes are likely to be underestimated. These results support the role of a substantial population reduction in salt intake for the prevention of cardiovascular disease.

\section{INTRODUCTION}

During the past century, the evidence for the risks imposed on human health by excess salt consumption has become compelling. The causal relation between intake in people with and without hypertension. ${ }^{1}$ Based on the effects of high salt intake on blood pressure and on the prominent role of high blood pressure in promoting cardiovascular diseases, it has been suggested that a population-wide reduction in salt intake could substantially reduce the incidence of cardiovascular disease. ${ }^{2}$ On the basis of the results of a meta-analysis of randomised controlled trials of salt reduction, ${ }^{3}$ it was estimated that a reduction in habitual dietary salt intake of $6 \mathrm{~g}$ a day would be associated with reductions in systolic/diastolic blood pressure of 7/4 $\mathrm{mm} \mathrm{Hg}$ in people with hypertension and 4/2 mm $\mathrm{Hg}$ in those without hypertension. At the population level these reductions in blood pressure could predict an average lower rate of $24 \%$ for stroke and $18 \%$ for coronary heart disease. ${ }^{4}$ Validation of these predictions by a randomised controlled trial of the effects of long term reduction in dietary salt on morbidity and mortality from cardiovascular disease would provide definite proof. At present, a study of this kind is not available and, in fact, it is extremely unlikely that it will ever be performed because of practical difficulties, the long duration required, and high costs. Nevertheless, prospective cohort studies performed in the past three decades that measured the levels of dietary salt intake at baseline and recorded the incidence of vascular events have provided important indirect evidence. Most of these studies found evidence of such relation, although few had enough power to attain statistical significance.

We performed a systematic review and meta-analysis of the prospective studies of habitual dietary salt intake and incidence of stroke and total cardiovascular 
disease using strictly predetermined criteria for inclusion or exclusion. We assessed whether or not the overall evidence in prospective studies supports the presence of a relation between levels of dietary salt intake and both stroke and cardiovascular outcomes and calculated an estimate of the risk.

\section{METHODS}

Data sources and searches

We performed a systematic search for publications using Medline (1966-2008), Embase (from 1988), AMED (from 1985), CINAHL (from 1982), Psychinfo (from 1985), and the Cochrane Library. Search strategies used subject headings and key words with no language restrictions. Further information was retrieved through a manual search of references from recent reviews and relevant published original studies. We examined reference lists of the relevant reviews, identified studies, and reviewed the cited literature..$^{5}$

\section{Study selection}

Two reviewers (LD and N-BK) independently extracted the data. Discrepancies about inclusion of studies and interpretation of data were resolved by arbitration (PS or FPC), and consensus was reached after discussion. In the case of missing data for potentially suitable studies, we contacted authors and asked them to provide the necessary information. To be included in the meta-analysis a published study had to be an original article published from January 1966 to December 2008 , be a prospective population study, assess salt intake as baseline exposure, determine either stroke or total cardiovascular disease prospectively as the outcome, follow participants for at least three years, include an adult population, and indicate the number of participants exposed and the rate or number of events in different categories of salt intake.

Of the 3246 publications retrieved, we identified 15 studies that met the inclusion criteria. One was a duplicate analysis of a single cohort previously described by the same authors ${ }^{67}$ and another ${ }^{8}$ referred to the same cohort (national health and nutrition examination survey (NHANES) I) analysed by other authors with more stringent criteria. ${ }^{9}$ We therefore included 13 studies in the meta-analysis that provided suitable data on 19 population samples $^{610-21}$ (tables 1 and 2).

\section{Data extraction}

From the identified studies and respective populations we recorded publication reference, total number of participants, country, sex, age (mean, median, or range), recruitment time, follow-up (years), outcome reported (stroke, cardiovascular disease) and method of outcome assessment, number (rate) of events, method of assessing salt intake, and level of salt intake in different categories.

Categorisation of salt intake differed among studies. Some reported the number of subjects exposed and the rate (number) of events across the distribution of salt intake; others reported differences in the event rate for a $100 \mathrm{mmol} /$ day difference in sodium intake, as in the studies by $\mathrm{He}$ et $\mathrm{al}^{9}$ and Tuomilehto et al. ${ }^{13}$ In the last two cases we used the relative risk or hazard ratio reported by the authors for the analysis. In all the cases in which categorisation of the study participants by level of salt intake was available, we calculated the relative risk of higher versus lower salt intake by comparing the event rate in the two categories with a difference in average salt intake closest to $100 \mathrm{mmol}$ of sodium or about $6 \mathrm{~g}$ of salt a day.

\section{Statistical analysis}

We evaluated the quality of the studies included in the meta-analysis with the Downs and Black score system. ${ }^{21}$ We extracted relative risks or hazard ratios from the selected publications and calculated their standard errors from the respective confidence intervals. The value from each study and the corresponding standard error were transformed into their natural logarithms to stabilise the variances and to normalise their distribution. The pooled relative risk (and 95\% confidence interval) was estimated with a random effect model, weighting for the inverse of the variance. ${ }^{22}$ The heterogeneity among studies was tested by $\mathrm{Q}$ statistic and quantified by $\mathrm{H}$ statistic and $\mathrm{I}^{2}$ statistic. $^{23}$ The influence of individual studies, from which the meta-analysis estimates are derived, was examined by omitting one study at a time to see the extent to which inferences depend on a particular study or group of studies (sensitivity analysis). Subgroup or meta-regression analyses were used to identify associations between risk of stroke or cardiovascular disease and relevant study characteristics (age and sex of participants, year of publication duration of follow-up, method of assessment of sodium intake, difference in sodium level, control for baseline blood pressure) as possible sources of heterogeneity. We used funnel plot asymmetry to detect publication bias and applied Egger's regression test to measure any asymmetry. ${ }^{2425}$ All statistical analyses were performed with MIX software version $1.7^{26}$ and Stata software for meta-regression analysis.

\section{RESULTS}

\section{Characteristics of the study cohorts}

We included in the meta-analysis 13 studies reporting on 19 independent cohorts (table 1). There were 177025 participants from six different countries (six studies from the United States, two each from Finland and Japan, one each from the Netherlands, Scotland, and Taiwan). Eleven studies recruited both male and female participants, while two studies included only men. Follow-up ranged from 3.5 to 19 years. Four studies reported only stroke events (either total stroke rate or stroke deaths), three only cardiovascular disease (total cardiovascular disease rate or cardiovascular disease deaths), and six reported both. Salt intake was assessed by 24 hour dietary recall $(n=4)$, food frequency questionnaire $(\mathrm{n}=4), 24$ hour urine excretion $(\mathrm{n}=4)$, and questionnaire $(\mathrm{n}=1)$. In total there were 5346 strokes reported and 5161 total cardiovascular disease events. Of the 11 studies that included both 
Table 1 |Characteristics of prospective studies included in meta-analysis of studies on salt intake and stroke and cardiovascular disease (CVD)

\begin{tabular}{|c|c|c|c|c|c|c|c|}
\hline Study & Age (years) & Sex & No of people & Outcome(s) & Outcome assessment & $\begin{array}{l}\text { Sodium intake } \\
\text { assessment }\end{array}$ & $\begin{array}{l}\text { Study quality } \\
\text { score }\end{array}$ \\
\hline $\begin{array}{l}\text { Kagan, } 1985 \text {, US } \\
\text { (Hawaii) }^{10}\end{array}$ & $45-68$ & Men & 7895 & Total stroke & $\begin{array}{l}\text { Physical examination for residual of stroke at } \\
\text { baseline, } 2 \text { and } 6 \text { year follow-up; surveillance of } \\
\text { hospital discharges and death certificates reviewed } \\
\text { by neurologist }\end{array}$ & $24 \mathrm{~h}$ dietary recall & 14 \\
\hline Hu, 1992, Taiwan ${ }^{11}$ & $\geq 36$ & Men and women & 8562 & Total stroke & $\begin{array}{l}\text { Case finding through local hospital referrals and study } \\
\text { nurses. Certification by computed tomography }\end{array}$ & $\begin{array}{l}\text { Household survey } \\
\text { questionnaire }\end{array}$ & 12 \\
\hline $\begin{array}{l}\text { Alderman, } 1995, \text { US, } \\
\text { occupational }^{6}\end{array}$ & $52 ; 54$ & Men; women & $1900 ; 1037$ & $\begin{array}{l}\text { Total CVD, } \\
\text { total stroke }\end{array}$ & $\begin{array}{l}\text { Review of hospital charts and death certificates (ICD- } \\
\text { 9): CVD I410, 1430-1434, 1436-1438; stroke as above } \\
\text { without 1410 }\end{array}$ & $\begin{array}{l}24 \mathrm{~h} \text { urine } \\
\text { collection }\end{array}$ & 12 \\
\hline $\begin{array}{l}\text { Tunstall-Pedoe, } \\
\text { 1997, Scotland }\end{array}$ & $40-59$ & Men; women & $5754 ; 5875$ & Total CVD & $\begin{array}{l}\text { Case notes requested for all hospital episodes of } \\
\text { myocardial infarction and other emergency admission } \\
\text { for coronary heart disease, then extracted and coded } \\
\text { according to MONICA project criteria }\end{array}$ & $\begin{array}{l}24 \mathrm{~h} \text { urine } \\
\text { collection }\end{array}$ & 15 \\
\hline $\begin{array}{l}\text { He, } 1999, \text { US, } \\
\text { NHANES I }\end{array}$ & $25-74$ & $\begin{array}{l}\text { Men; women; non- } \\
\text { overweight; } \\
\text { overweight }\end{array}$ & $\begin{array}{l}3686 ; 5799 \\
6797 ; 2688\end{array}$ & $\begin{array}{l}\text { CVD death, } \\
\text { total stroke, } \\
\text { stroke death }\end{array}$ & $\begin{array}{l}\text { Mortality based on death certificate reports. Incident } \\
\text { stroke based on death certificate reports in which } \\
\text { underlying cause of death was recorded with ICD-9 } \\
\text { code }(430-434.9,436 \text { or } 437.0-437.1) \text { or one or more } \\
\text { hospital stays with discharges with one of these } \\
\text { codes }\end{array}$ & $24 \mathrm{~h}$ dietary recall & 17 \\
\hline $\begin{array}{l}\text { Tuomilehto, 2001, } \\
\text { Finland }^{13}\end{array}$ & $25-64$ & Men; women & $1173 ; 1263$ & $\begin{array}{l}\text { CVD death. } \\
\text { total stroke }\end{array}$ & $\begin{array}{l}\text { National hospital discharge register ICD-8 and ICD-9, } \\
430-438 \text {, and 390-448 }\end{array}$ & $\begin{array}{l}24 \mathrm{~h} \text { urine } \\
\text { collection }\end{array}$ & 18 \\
\hline $\begin{array}{l}\text { Nagata, 2004, } \\
\text { Japan }^{14}\end{array}$ & $\geq 35$ & Men; women & $13355 ; 15724$ & Stroke death & National vital statistics ICD-9 430-448 & FFQ & 18 \\
\hline $\begin{array}{l}\text { Cohen, 2006, US, } \\
\text { NHANES } \|^{15}\end{array}$ & $30-74$ & Men and women & 7154 & $\begin{array}{l}\text { CVD death, } \\
\text { stroke death }\end{array}$ & $\begin{array}{l}\text { Mortality based on death certificate reports ICD-9 } \\
430-438\end{array}$ & $24 \mathrm{~h}$ dietary recall & 18 \\
\hline $\begin{array}{l}\text { Geleijnse, } 2007 \\
\text { Netherlands }^{16}\end{array}$ & $\geq 55$ & Men and women & 1448 & $\begin{array}{l}\text { CVD death, } \\
\text { total stroke }\end{array}$ & $\begin{array}{l}\text { GPs registries (ICD-10): I20-125,146,149,150,160-167, } \\
\text { I70-174 and R96; 160-167 }\end{array}$ & $\begin{array}{l}\text { FFQ and overnight } \\
\text { urine sodium }\end{array}$ & 15 \\
\hline $\begin{array}{l}\text { Cook, 2007, US, } \\
\text { TOHPI, USA, TOHP }{ }^{17}\end{array}$ & $30-54 ; 30-54$ & $\begin{array}{l}\text { Men and women; } \\
\text { men and women }\end{array}$ & $542 ; 1873$ & Total CVD & $\begin{array}{l}\text { Notification of non-fatal outcomes in post-trial } \\
\text { surveillance, review by physician plus National Death } \\
\text { Index }\end{array}$ & $\begin{array}{l}24 h \text { urine } \\
\text { collection }\end{array}$ & 12 \\
\hline $\begin{array}{l}\text { Larsson, 2008, } \\
\text { Finland }^{18}\end{array}$ & $50-69$ & Men (smokers) & 26,556 & Total stroke & $\begin{array}{l}\text { Discharge diagnoses and death certificates (ICD-8, } 9 \text {, } \\
\text { and 10) }\end{array}$ & FFQ & 15 \\
\hline $\begin{array}{l}\text { Umesawa, 2008, } \\
\operatorname{Japan}^{19}\end{array}$ & $40-79$ & Men; women & $23119 ; 35611$ & $\begin{array}{l}\text { CVD death, } \\
\text { stroke death }\end{array}$ & National Vital Statistics ICD-9 & $\begin{array}{l}\text { FFQ } 4 \times 3 \text { day } \\
\text { dietary records }\end{array}$ & 18 \\
\hline $\begin{array}{l}\text { Cohen, } 2008 \text {, US, } \\
\text { NHANES } \|^{20}\end{array}$ & $\geq 30$ & Men and women & 8699 & Total CVD & Vital status and cause of death (ICD-9 and ICD-10) & $24 \mathrm{~h}$ dietary recall & 18 \\
\hline
\end{tabular}

men and women, five reported outcomes separately. ${ }^{6913-15}$ The TOHP study included two different cohorts (I and II $)^{17}$ and the study by He and coworkers provided separate findings for men and women or, alternatively, for normal weight and overweight participants. ${ }^{9}$ Overall, data on the relation between salt consumption and stroke were available from 14 cohorts and on the relation between salt intake and cardiovascular disease from 14 cohorts.

The overall study quality, evaluated by the Downs and Black score, averaged 15.5 (range 12-18) on a scale of 19 (table 1).

\section{Salt intake and risk of stroke}

Table 2 provides data on the relation between salt intake and risk of stroke in each of the 14 cohorts included in our study. Figure 1 shows the results of the pooled analysis. In the pooled analysis, higher salt intake was associated with greater risk of stroke (relative risk 1.23, 95\% confidence interval 1.06 to 1.43 ; $\mathrm{P}=0.007)$. There was significant heterogeneity between studies $\left(\mathrm{P}=0.04 ; \mathrm{I}^{2}=61 \%\right)$. The funnel plot did not show asymmetry, thus excluding publication bias (Egger's test $\mathrm{P}=0.26$; see appendix on bmj.com). As shown in figure 1 for the individual cohorts included in the analysis, we found a trend towards a direct association between salt intake and risk of stroke in nine cohorts, which was significant in four. We observed a non-significant inverse trend in three cohorts.

Sensitivity analysis showed that the pooled estimate of the effect of salt intake on risk of stroke did not vary substantially with the exclusion of any one study; in particular, the exclusion of the study by Umesawa et al, ${ }^{19}$ which accounted for about $40 \%$ of all participants in the meta-analysis and nearly $20 \%$ of all strokes, resulted in a pooled relative risk of 1.19 (1.03 to 1.39), $\mathrm{P}=0.022$.

\section{Salt intake and risk of cardiovascular disease}

Table 2 provides data on the association between salt intake and the risk of cardiovascular disease in 14 cohorts. In the pooled analysis, there was an association between higher salt intake and risk of cardiovascular disease $(1.14,0.99$ to $1.32 ; \mathrm{P}=0.07$ ) (fig 2). The heterogeneity between studies was significant $\left(\mathrm{P}<0.01 ; \mathrm{I}^{2}=80 \%\right)$, but the funnel plot did not show asymmetry, thus excluding publication bias (Egger's test: $\mathrm{P}=0.39$; see appendix on bmj.com). The 
Table 2 | Detailed outcome of studies on salt intake and stroke and cardiovascular disease (CVD)

\begin{tabular}{|c|c|c|c|c|c|c|}
\hline \multirow[b]{2}{*}{ Study } & \multirow[b]{2}{*}{ Comparison } & \multicolumn{2}{|r|}{ All CVD } & \multicolumn{2}{|c|}{ All stroke } & \multirow[b]{2}{*}{ Factors controlled for in multivariate analysis } \\
\hline & & Events & $\operatorname{RR}(95 \% \mathrm{CI})$ & Events & $\operatorname{RR}(95 \% \mathrm{CI})$ & \\
\hline Kagan, $1985^{10}$ & Fifth $(V \vee I)$ & - & - & 238 & $0.92(0.60$ to 1.42$)$ & Age \\
\hline $\mathrm{Hu}, 1992^{11}$ & Salty food (yes $v$ no) & 一 & 一 & 104 & 1.79 (1.18 to 2.70$)$ & Age \\
\hline Alderman, $1995^{6}$ & Quarter $(|\mathrm{V} v|)$ in men & 96 & 0.37 (0.18 to 0.75$)$ & 17 & 0.59 (0.10 to 3.43$)$ & \multirow[b]{2}{*}{ Unadjusted } \\
\hline Alderman, $1995^{6}$ & $\begin{array}{l}\text { Quarter }(\mathrm{IV} v \mathrm{I}) \text { in } \\
\text { women }\end{array}$ & 21 & $2.29(0.44$ to 11.90$)$ & 6 & 2.10 (1.01 to 4.33$)$ & \\
\hline Tunstall-Pedoe, $1997^{12}$ & $\begin{array}{l}\text { Difference in men } \\
\text { between fifths }\end{array}$ & 404 & $1.05(0.97$ to 1.14$)$ & - & - & \multirow[b]{2}{*}{ Age } \\
\hline Tunstall-Pedoe, $1997^{12}$ & $\begin{array}{l}\text { Difference in women } \\
\text { between fifths }\end{array}$ & 177 & 1.16 (1.01 to 1.33$)$ & - & - & \\
\hline He, $1999^{9}$ & $\begin{array}{l}\text { Continuous variable } \\
\text { (men, women) }\end{array}$ & 895 & $\begin{array}{l}1.67(1.27 \text { to } 2.19), \\
1.54(1.12 \text { to } 2.10)\end{array}$ & - & - & \multirow{2}{*}{$\begin{array}{l}\text { Age, sex, race, SBP, cholesterol, BMI, diabetes, } \\
\text {-diuretic use, education, alcohol, smoking, total } \\
\text { energy intake }\end{array}$} \\
\hline $\mathrm{He}, 1999^{9}$ & Continuous variable & - & - & $\begin{array}{l}430 \text { overweight, } \\
250 \text { normal weight }\end{array}$ & $\begin{array}{l}0.99(0.81 \text { to } 1.20) \\
1.39(1.10 \text { to } 1.76)\end{array}$ & \\
\hline Tuomilehto, $2001^{13}$ & $\begin{array}{l}\text { Continuous variable } \\
\text { (men) }\end{array}$ & 72 & 1.38 (1.05 to 1.81$)$ & 43 & 1.00 (0.68 to 1.48$)$ & \multirow{2}{*}{$\begin{array}{l}\text { Age, study year, smoking, total cholesterol, HDL } \\
\text { cholesterol, SBP, BMI }\end{array}$} \\
\hline Tuomilehto, $2001^{13}$ & $\begin{array}{l}\text { Continuous variable } \\
\text { (women) }\end{array}$ & 15 & $1.43(0.74$ to 2.79$)$ & 41 & 1.34 (0.87 to 2.06$)$ & \\
\hline Nagata, $2004^{14}$ & Thirds (III $v \mid$ ) in men & - & - & 137 & 2.34 (1.23 to 4.47$)$ & \multirow{2}{*}{$\begin{array}{l}\text { Age, marital status, education, BMI, smoking, } \\
\text { alcohol, exercise, hypertension, diabetes, intake } \\
\text { of protein, total energy, vitamins K and E }\end{array}$} \\
\hline Nagata, $2004^{14}$ & Thirds (III $v \mid$ ) in women & - & - & 132 & 1.70 (0.96 to 3.00$)$ & \\
\hline Cohen, $2006^{15}$ & $\begin{array}{l}\text { Above } v \text { below median } \\
\text { sodium intake }\end{array}$ & 541 & 0.88 (0.74 to 1.05$)$ & 79 & $0.56(0.28$ to 1.11$)$ & $\begin{array}{l}\text { Age, sex, race, smoking, alcohol, SBP, BMI, } \\
\text { education, exercise, potassium and calories } \\
\text { intake, diabetes, cholesterol, anti-hypertensive } \\
\text { treatment. }\end{array}$ \\
\hline Geleijnse, $2007^{16}$ & Continuous variable & 217 & 0.77 (0.60 to 0.99$)$ & 181 & 1.08 (0.81 to 1.45$)$ & $\begin{array}{l}\text { Age, sex, creatinine and potassium excretion, } \\
\text { BMI, smoking, diabetes, diuretic use, education, } \\
\text { energy intake, alcohol, calcium, saturated fat. }\end{array}$ \\
\hline Cook I, $2007^{17}$ & $\begin{array}{l}\text { Habitual } v \text { reduced salt } \\
\text { intake }\end{array}$ & 49 & 2.53 (1.30 to 4.94$)$ & - & - & \multirow{2}{*}{$\begin{array}{l}\text { Age, race, sex, weigh loss, baseline weight, } \\
\text { sodium excretion }\end{array}$} \\
\hline Cook II, $2007^{17}$ & $\begin{array}{l}\text { Habitual } v \text { reduced salt } \\
\text { intake }\end{array}$ & 151 & 1.12 (0.78 to 1.59$)$ & - & - & \\
\hline Larsson, $2008^{18}$ & Fifths ( $\vee v 1)$ & - & - & 2702 & 1.04 (0.93 to 1.17$)$ & $\begin{array}{l}\text { Age, supplementation group, smoking, BMI, SBP } \\
\text { and DBP, total cholesterol, HDL cholesterol, } \\
\text { diabetes, CHD, exercise, alcohol, energy intake }\end{array}$ \\
\hline Umesawa, $2008^{19}$ & Fifth $(V \vee I)$ & 2087 & 1.42 (1.19 to 1.69$)$ & 986 & 1.55 (1.20 to 2.00$)$ & $\begin{array}{l}\text { BMI, smoking, alcohol, hypertension, diabetes, } \\
\text { menopause, hormone therapy, exercise, } \\
\text { education, mental stress, calcium and } \\
\text { potassium intake }\end{array}$ \\
\hline Cohen, $2008^{20}$ & Continuous variable & 436 & 0.88 (0.77 to 1.01$)$ & - & - & $\begin{array}{l}\text { Age, sex, race, education, added table salt, } \\
\text { exercise, alcohol, smoking, diabetes, cancer, } \\
\text { SBP, cholesterol, potassium intake, weight, anti- } \\
\text { hypertensive treatment }\end{array}$ \\
\hline
\end{tabular}

$\mathrm{SBP}=$ systolic blood pressure, $\mathrm{DBP}=$ diastolic blood pressure, $\mathrm{BMI}=$ body mass index, $\mathrm{HDL}=$ high density lipoprotein, $\mathrm{CHD}=$ coronary heart disease .

evaluation of individual studies showed a trend towards a direct association between salt intake and risk of cardiovascular disease in 10 cohorts, with significantly higher relative risk in six. An inverse trend was observed in four cohorts and was significant in one. Sensitivity analysis showed that the exclusion of the only study showing a significant inverse trend ${ }^{6}$ led to a pooled estimate of relative risk of 1.17 (1.02 to 1.34), $\mathrm{P}=0.02$ (fig 2). Further exclusion of the study by Umesawa et al, ${ }^{19}$ which accounted for over $50 \%$ of all participants and about $40 \%$ of all cardiovascular disease events led to a pooled relative risk of 1.14 (0.99 to 1.31), $\mathrm{P}=0.06$.

\section{Sources of heterogeneity}

Age-Meta-regression analyses indicated no association between mean age of study participants and effect of sodium intake on the risk of stroke: $\exp (b)=1.01$
(0.99 to 1.03). Likewise, meta-regression showed no association between age and effect of sodium intake on the risk of cardiovascular disease: $\exp (b)=0.99$ (0.97 to 1.02$)$.

Sex-Three studies reported data for men and women separately for incidence of stroke. ${ }^{61314}$ The pooled estimates from these three studies were 1.30 (0.64 to $2.65 ; \mathrm{P}=0.47$ ) and 1.56 (1.14 to $2.13 ; \mathrm{P}<0.01$ ), respectively. Three studies reported data for men and women separately for incidence of cardiovascular disease. $^{91213}$ The pooled estimates were 1.31 ( 0.97 to $1.77 ; \mathrm{P}=0.08$ ) and 1.27 (1.05 to $1.55 ; \mathrm{P}=0.01$ ), respectively.

Method of assessment of sodium intake - In nine cohorts that used food frequency questionnaires or dietary recall for the evaluation of habitual sodium intake the pooled risk estimate for stroke was 1.25 (1.03 to 1.51; $\mathrm{P}=0.02){ }^{10-1214151819}$ In five cohorts that used 24 hour 


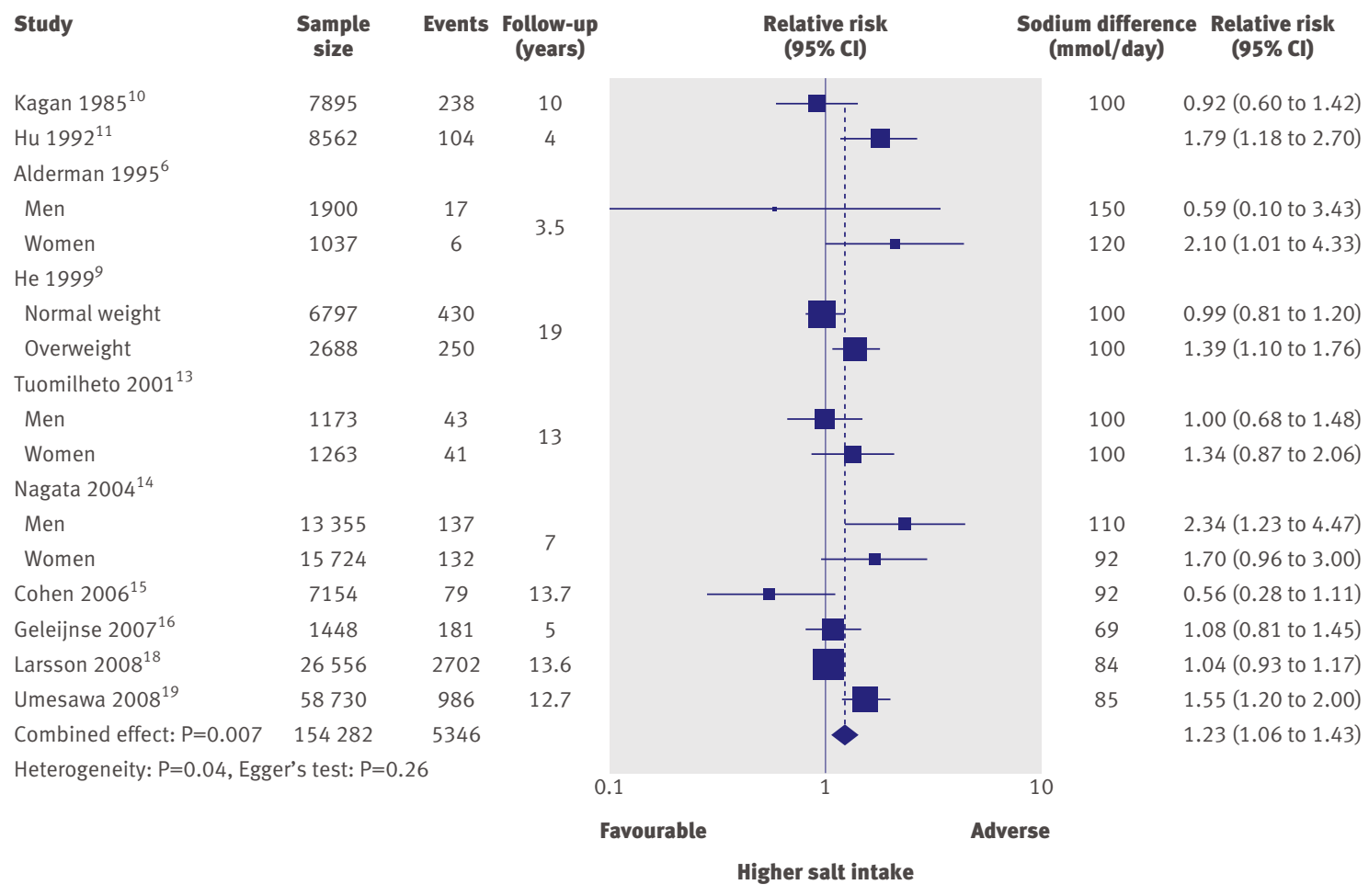

Fig 1 Risk of incident stroke associated with higher compared with lower salt intake in 14 population cohorts from 10 published prospective studies including 154282 participants and 5346 events

urine collection the pooled risk estimate was $1.16(0.94$ to $1.44 ; \mathrm{P}=0.17) .{ }^{6}{ }^{13}$ In five cohorts that used food frequency questionnaires or dietary recall the pooled estimate for cardiovascular disease was 1.21 (0.92 to 1.59; $\mathrm{P}=0.17),{ }^{9151920}$ and in nine cohorts that used 24 hour urine collection the pooled risk estimate for cardiovascular disease was $1.10 \quad(0.92$ to $1.31 ; \quad \mathrm{P}=$ 0.32). ${ }^{612} 131617$

Baseline blood pressure or hypertension status - In the studies that provided relative risk estimates adjusted for baseline blood pressure or hypertension status, the pooled relative risk was 1.22 (1.02 to $1.45 ; \mathrm{P}=0.03$ ) for stroke (nine cohorts) and 1.25 (0.99 to 1.57; $\mathrm{P}=0.06$ ) for cardiovascular disease (seven cohorts).

Baseline body mass index (BMI) or body weight-In the studies that provided relative risk estimates adjusted for baseline BMI or body weight, the pooled relative risk was 1.20 (1.02 to $1.40 ; \mathrm{P}=0.02)$ for stroke $(10$ cohorts) and 1.22 (1.00 to $1.49 ; \mathrm{P}=0.05)$ for cardiovascular disease (10 cohorts).

Length of follow-up-Meta-regression analysis showed a significant association between duration of follow-up and the effect of sodium on the risk of stroke. The log relative risk was estimated to increase by 0.07 per increase of one year of follow-up: $\exp (b)=1.07$ (1.04 to 1.10). The estimated variance between studies (heterogeneity) was reduced from 0.05 to 0.02 . In contrast, however, we found no association between duration of follow-up and effect of sodium on the risk of cardiovascular disease: $\exp (\mathrm{b})=0.98$ (0.95 to 1.02).

Dose-response analysis-Variance weighted least squares regression of the risk of stroke on the study specific difference between higher and lower categories of sodium intake (differences in sodium intake values reported in table 2) provided evidence of a significant direct association $(\exp (b)=1.06(1.03$ to 1.10$))$, indicating a $6 \%$ increase in the rate of stroke for every $50 \mathrm{mmol} /$ day difference in sodium intake. There was a similar trend for the risk of cardiovascular disease (exp (b)=1.19 (0.69 to 2.07)), that was not significant.

Time trend (year of publication) - Starting with the first published study ${ }^{10}$ we calculated the cumulative pooled relative risk by stepwise addition of the results of the other available studies up to the last one published in July 2008. ${ }^{19}$ Figure 3 shows the results of these cumulative meta-analyses. The pooled relative risk for stroke stabilised early in the 1.20-1.30 interval and achieved significance starting in 2001. Similar results were obtained in the analysis of cardiovascular disease, for which the pooled relative risk estimate also stabilised early and close to the final value, achieving significance starting in 1999.

\section{DISCUSSION}

This meta-analysis shows unequivocally that higher salt intake is associated with a greater incidence of strokes and total cardiovascular events. Our systematic review identified 13 relevant and suitable studies published from 1996 to 2008 . These studies provided evidence from 170000 people contributing overall more than 10000 vascular events.

Cardiovascular diseases are the major cause of death among people aged over 60 and second among those aged 15-59. According to the World Health 


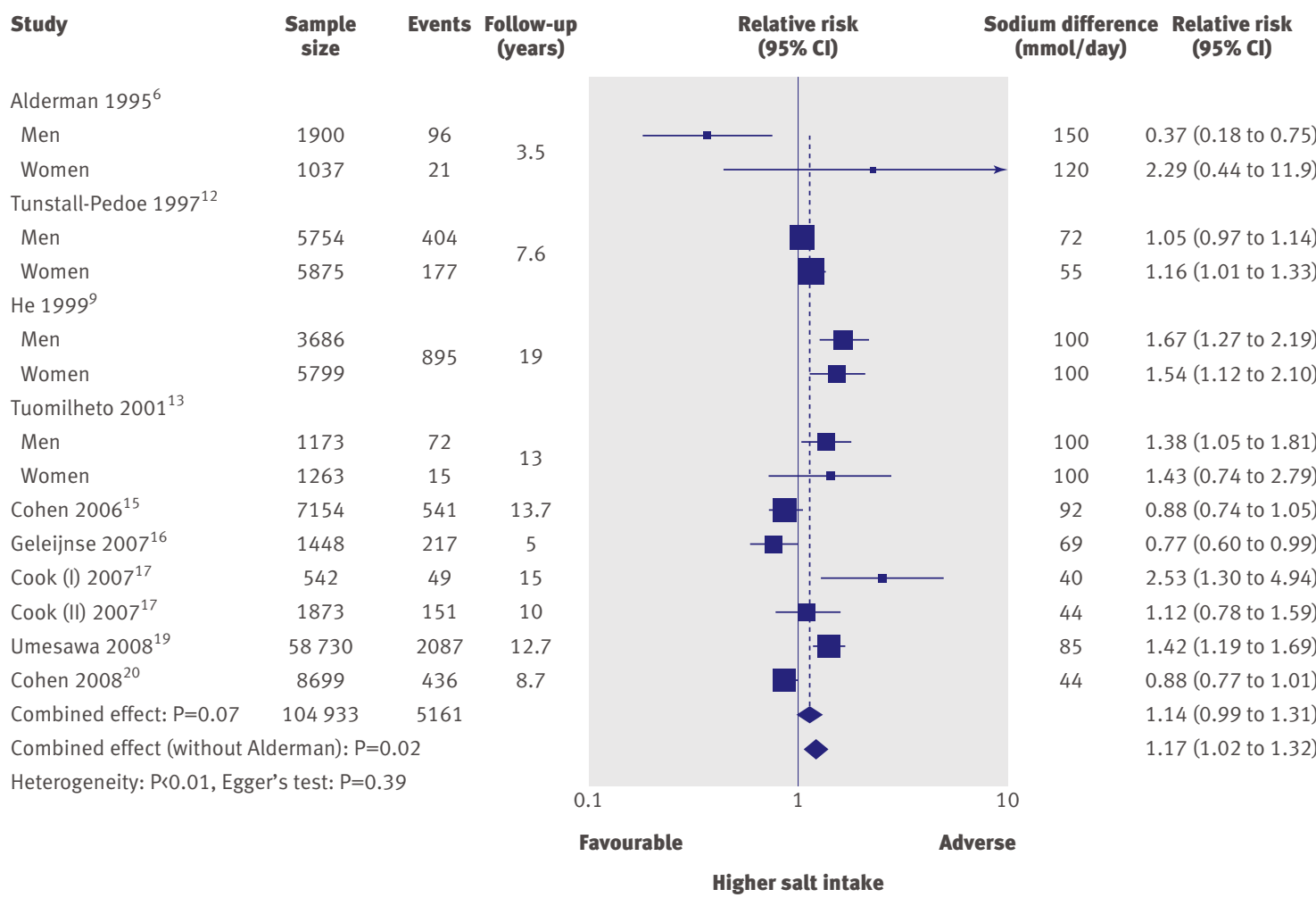

Fig 2 | Risk of incident cardiovascular disease associated with higher compared with lower salt intake in 14 population cohorts from nine published prospective studies including 104132 participants and 5161 events. Pooled analysis after the exclusion of the study by Alderman et $\mathrm{al}^{6}$ (men and women), including 102086 participants and 5044 events

Organization, $62 \%$ of all strokes and $49 \%$ of coronary heart disease events are attributable to high blood pressure. ${ }^{27}$ The direct causal relation between levels of dietary salt intake and blood pressure at the population level has also been recognised. ${ }^{12829}$ Given the graded causal relation between blood pressure and cardiovascular disease, beginning at around $115 \mathrm{~mm}$ $\mathrm{Hg}$ systolic pressure, ${ }^{30}$ it is reasonable to expect considerable benefit on the rate of cardiovascular disease from a reduction in salt intake.

\section{Association between salt intake, stroke, and cardiovascular disease}

The results of this meta-analysis provide evidence of a direct association between high dietary salt intake and risk of stroke. Despite the considerable heterogeneity between the 14 cohorts available for the analysis, the results are strengthened by the lack of major publication bias and by the observation of a significant association in four individual cohorts included in the analysis, whereas in none was an inverse statistical association apparent. The pooled relative risk indicates a $23 \%$ greater risk of stroke for an average difference in sodium intake (weighted for the population size of each study) of $86 \mathrm{mmol}$ (equivalent to about $5 \mathrm{~g}$ of salt a day). Sensitivity analysis with the exclusion of a single study, on the basis of its particular weight with regard to both number of participants and events, only moderately reduced the difference in risk (from 23\% to 19\%), which remained significant.
Likewise, the pooled analysis of the 12 cohorts for which data on cardiovascular disease outcome were available (after the exclusion of a single outlier) showed a direct association between higher salt intake and risk of cardiovascular disease, with a pooled relative risk of 1.17. ${ }^{4} \mathrm{~A}$ trend in this direction occurred in as many as nine of the 12 cohorts and was significant in six. There was an inverse trend in three cohorts..$^{151620}$ The study by Alderman et al, ${ }^{6}$ showing a relative risk in men of 0.37 , has been challenged because of the low number of events recorded and several methodological inadequacies, the most important being the evaluation of habitual salt consumption on the basis of 24 hour urine collection obtained shortly after the study participants had been instructed to reduce their usual level of sodium intake. ${ }^{31}$ The results of sensitivity analysis indicate that the exclusion of this single study from our meta-analysis strengthens the estimate. The additional exclusion of a large Japanese cohort providing a high proportion of participants and events overall ${ }^{19}$ only slightly reduced the pooled relative risk estimate (from 1.17 to 1.14 ) and the level of significance (to $0.06)$.

\section{Evaluation of main sources of heterogeneity}

We used subgroup and meta-regression analyses to assess the influence of several factors on the association between habitual sodium intake and risk of stroke or cardiovascular disease. For both stroke and cardiovascular disease outcomes, separate analyses of the 


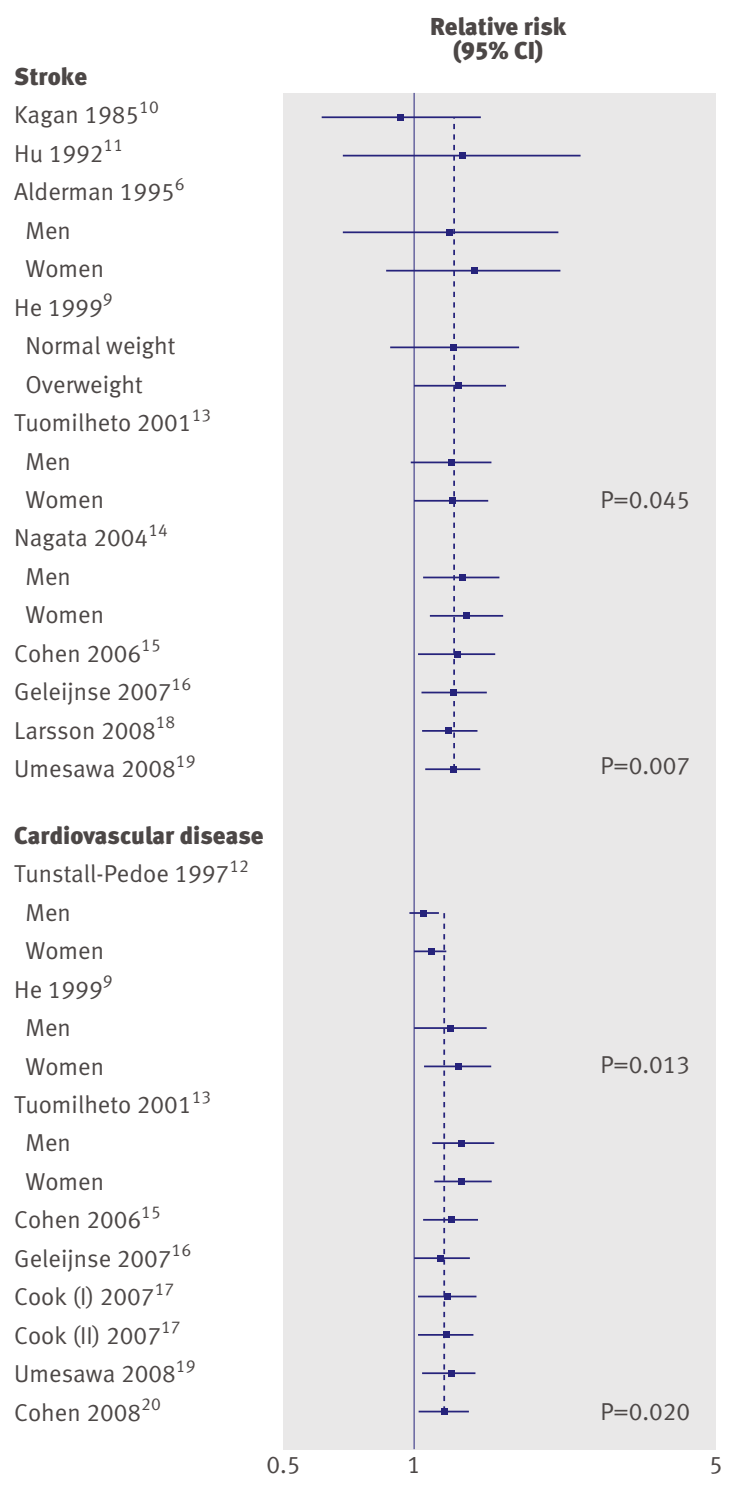

Fig 3 | Cumulative meta-analysis. Evaluation of time trends (year of publication) in relation between habitual sodium intake and risk of stroke or cardiovascular disease

male and female cohorts suggest that the associations are consistent and not significantly different between the sexes. Similar results were obtained with respect to the method of assessment of habitual sodium intake used in the various studies.

Eight studies provided data adjusted for baseline blood pressure or hypertension status. Separate evaluations of these studies provided relative risk estimates for both stroke and cardiovascular disease similar to those obtained for the total number of studies included in the meta-analysis. This finding seems at variance with the hypothesis that the effect of salt on cardiovascular risk is substantially mediated by its unfavourable action on blood pressure. Adjustment for baseline blood pressure or hypertension status only partially corrects for the overall influence of blood pressure on the study results in as much as it does not account for changes in blood pressure occurring during the observation period, a problem more relevant the longer the follow-up period. Part of the association observed, however, might be mediated by factors other than blood pressure, and there is evidence in the literature of deleterious effects of high salt intake on left ventricular mass, ${ }^{32-34}$ arterial stiffness, ${ }^{35}$ and renal function, ${ }^{3637}$ which are not totally explained by its effect on blood pressure.

Overweight and obesity are often associated with high blood pressure and are causally involved in the development of hypertension. ${ }^{38}$ Nine out of 13 studies included in the meta-analysis provided relative risk estimates adjusted for BMI or body weight at entry into the study. ${ }^{914-21}$ Therefore, as for blood pressure, the association between habitual sodium intake and risk of stroke and cardiovascular disease seems partly independent from the influence of excess body weight. Two studies, however, reported a significant interaction between overweight and habitual sodium intake on the risk of cardiovascular events. ${ }^{913}$ This finding is consistent with the description of alterations in renal tubular sodium handling in obese individuals, making them particularly sensitive to the effects of high salt intake. $^{39}$

\section{Study limitations}

The studies included in our meta-analysis were heterogeneous regarding sample size, number of events, and duration of follow-up, with a few cohorts having small numbers. In the calculation of the pooled relative risk we weighted the results of the individual studies for sample size but did not account for the duration of follow-up. Our meta-regression analysis indicated that the longer the follow-up the greater the effect of habitual sodium intake on the risk of stroke but not, apparently, on the risk of total cardiovascular events. Possible explanations for this discrepancy are the higher mean age at occurrence of stroke, which would increase the chances of an event the longer the follow-up, and the closer relation of high blood pressure to stroke compared with other types of vascular events.

The estimate of the baseline population salt intake in each study was based on a single measurement (whether through 24 hour urine collection or dietary assessment). We were therefore unable to correct for regression dilution bias. Because of the large day to day variability within people in salt consumption and the consequent diluting effect imposed on the average estimate of exposure, our estimates of risk are probably underestimated.

Categorisation of salt intake was also heterogeneous: some studies stratified the population by categories of sodium intake and compared cardiovascular outcomes across categories, other studies gave a difference in outcome for a given difference (for example, $100 \mathrm{mmol} / 24 \mathrm{~h}$ ) in sodium intake or excretion. To standardise our comparison between higher and lower salt consumption we sought to refer to a difference as close as possible to $100 \mathrm{mmol}$ or $6 \mathrm{~g}$ a day 


\section{WHAT IS ALREADY KNOWN ON THIS TOPIC}

Experimental, epidemiological, migration, and intervention studies have shown a causal relation between habitual dietary salt intake and blood pressure

Population based intervention studies and meta-analyses of randomised controlled trials have shown that it is possible to achieve significant reductions in blood pressure with reduced salt intake in both hypertensive and normotensive individuals

\section{WHAT THIS STUDY ADDS}

Higher salt intake is associated with significantly greater incidence of strokes and total cardiovascular events, with a dose dependent association

A difference of $5 \mathrm{~g}$ a day in habitual salt intake is associated with a $23 \%$ difference in the rate of stroke and $17 \%$ difference in the rate of total cardiovascular disease

Each year a $5 \mathrm{~g}$ reduction in daily salt intake at the population level could avert some one and a quarter million deaths from stroke and almost three million deaths from cardiovascular disease worldwide more effective implementation of public health policies has been the historical opposition of the food industry, ${ }^{44}$ based on the arguments that the available evidence does not show significant benefits on hard end points at a population level from a moderate reduction in salt intake. Our study now clearly addresses those doubts. Some progress has been made in the past few years by closer collaboration between governments, public health bodies, and some sectors of the industry on a "voluntary" basis, as in the UK, with the reformulation of many food items towards a lower salt content and proposals of improved labelling. These efforts have led to a reduction of $0.9 \mathrm{~g} \mathrm{a}$ day (or about 10\%) in population salt intake in four years (from 9.5 to $8.6 \mathrm{~g}$ a day), still far from the recommended $6 \mathrm{~g}$ a day initial targets that were set in the UK. While the voluntary approach is the preferred choice for many governments, the "regulatory" approach has advantages ${ }^{45}$ sometimes being the most efficient, effective, and cost effective way of achieving public health targets. ${ }^{41-43}$ For population salt intake to approach the recommended targets within a reasonable time frame, an "upstream" approach is now necessary alongside the traditional "downstream" public health approach based on health promotion and behavioural changes.

Contributors: PS and FPC conceived the study aims and design, contributed to the systematic review and data extraction, performed the analysis, interpreted the results, and drafted the manuscript. LD'E and NBK contributed to the data extraction, interpretation of results, and revision of the manuscript. PS is guarantor.

Funding: This study was funded in part by an EC Grant (FP7-HEALTH2007-201550). The publication does not necessarily represent the decisions or the stated policy of WHO and the designations employed and the presentation of the material do not imply the expression of any opinion on the part of $\mathrm{WHO}$

Competing interests: None declared.

Ethical approval: Not required

Data sharing: Search strategy and flow chart are available from the corresponding authors by e-mail.

A reduction of $5 \mathrm{~g}$ (about one teaspoon) of salt woulc bring consumption close to the WHO recommended level ( $5 \mathrm{~g}$ a day at the population level).

According to a recent report of the World Heart Federation there are over 5.5 million deaths a year from stroke throughout the world and close to 17.5 million deaths a year from cardiovascular disease. ${ }^{40}$ Given that the case fatality rates for stroke is estimated at one in three and those for total cardiovascular disease at one in five, a $23 \%$ reduction in the rate of stroke and a $17 \%$ overall reduction in the rate of cardiovascular disease attributable to a reduction in population salt intake could avert some one and a quarter million deaths from stroke and almost three million deaths from cardiovascular disease each year. Many studies have also shown that a reduction in salt intake is cost effective, ${ }^{41-43}$ arguing for the more widespread introduction of national programmes to reduce dietary salt consumption. In recent years, a few countries have made some progress towards reduction of habitual salt intake through a voluntary approach ${ }^{1}$ or by regulation, as in Finland, ${ }^{42}$ but levels of salt consumption are still far from the WHO recommended targets. There are many reasons for these delays. One barrier to a
1 He FJ, MacGregor GA. A comprehensive review on salt and health and current experience of worldwide salt reduction programmes. J Hum Hypertens 2009;23:363-84.

2 World Health Organization. Reducing salt intake in populations: report of a WHO forum and technical meeting. WHO, 2007:1-60.

3 He FJ, MacGregor GA. Effect of modest salt reduction on blood pressure: a meta-analysis of randomized trials. Implications for public health. J Hum Hypertens 2002;16:761-70.

4 He FJ, MacGregor GA. How far should salt intake be reduced? Hypertension 2003;42:1093-9.

5 Moher D, Cook DJ, Eastwood S, Olkin I, Rennie D, Stroup DF. Improving the quality of reports of meta-analyses of randomised controlled trials: the QUOROM statement. Quality of reporting of meta-analyses. Lancet 1999;354:1896-900.

6 Alderman MH, Madhavan S, Cohen H, Sealey JE, Laragh JH. Low urinary sodium is associated with greater risk of myocardial infarction among treated hypertensive men. Hypertension 1995;25:1144-52.

7 Alderman MH, Sealey JE, Cohen $\mathrm{H}$, Madhavan S and Laragh JH. Urinary sodium excretion and myocardial infarction in hypertensive patients: a prospective cohort study. Am J Clin Nutr 1997;65(suppl):682-6S.

8 Alderman MH, Cohen H, Madhavan S. Dietary sodium intake and mortality: the national health and nutrition examination survey (NHANES I). Lancet 1998;351:781-5.

9 He J, Ogden LG, Vupputuri S, Bazzano LA, Loria C, Whelton PK. Dietary sodium intake and subsequent risk of cardiovascular disease in overweight adults. JAMA 1999;282:2027-34.

10 Kagan A, Popper JS, Rhoads GG, Yano K. Dietary and other risk factors for stroke in Hawaiian Japanese men. Stroke 1985;16:390-6. 
$11 \mathrm{Hu} \mathrm{HH}$, Sheng WY, Chu FL, Lan CF, Chiang BN. Incidence of stroke in Taiwan. Stroke 1992;23:1237-41.

12 Tunstall-Pedoe H, Woodward M, Tavendale R, A'Brook R, McCluskey MK. Comparison of the prediction by 27 different factors of coronary heart disease and death in men and women of the Scottish heart health study: cohort study. BMJ 1997;315:722-9.

13 Tuomilehto J, Jousilahti P, Rastenyte D, Moltchanov V, Tanskanen A Pietinen, $P$, et al. Urinary sodium excretion and cardiovascular mortality in Finland: a prospective study. Lancet 2001;357:848-51.

14 Nagata C, Takatsuka N, Shimizu N, Shimizu H. Sodium intake and risk of death from stroke in Japanese men and women. Stroke 2004;35:1543-7.

15 Cohen HW, Hailpern SM, Fang J, Alderman MH. Sodium intake and mortality in the NHANES II follow-up study. Am J Med 2006;119:275 e7-14.

16 Geleijnse JM, Witteman JC, Stijnen T, Kloos MW, Hofman A, Grobbee DE. Sodium and potassium intake and risk of cardiovascular events and all-cause mortality: the Rotterdam study. Eur J Epidemiol 2007;22:763-70.

17 Cook NR, Cutler JA, Obarzanek E, Buring JE, Rexrode KM, Kumanyika SK, et al. Long term effects of dietary sodium reduction on cardiovascular disease outcomes: observational follow-up of the trials of hypertension prevention (TOHP). BMJ 2007;33:885-8.

18 Larsson SC, Virtanen MJ, Mars M, Mannisto S, Pietinen P, Albanes D, et al. Magnesium, calcium, potassium, and sodium intakes and risk of stroke in male smokers. Arch Intern Med 2008;168:459-65.

19 Umesawa M, Iso H, Date C, Yamamoto A, Toyoshima H, Watanabe Y, et al. Relations between dietary sodium and potassium intakes and mortality from cardiovascular disease: the Japan collaborative cohor study for evaluation of cancer risks. Am J Clin Nutr 2008;88:195-202.

20 Cohen HW, Hailpern SM, Alderman MH. Sodium intake and mortality follow-up in the third national health and nutrition examination survey (NHANES III). J Gen Intern Med 2008;23:1297-302.

21 Downs SH, Black N. The feasibility of creating a checklist for the assessment of the methodological quality both of randomised and non-randomised studies of health care interventions. J Epidemiol Community Health 1998;52:377-84.

22 Dersimonian R, Laird N. Meta-analysis in clinical trials. Control Clin Trials 1986;7:177-88.

23 Higgins JP, Thompson SG, Deeks JJ, Altman DG. Measuring inconsistency in meta-analyses. BM/ 2003;327:557-60.

24 Egger M, Davey SG, Schneider M, Minder C. Bias in meta-analysis detected by a simple, graphical test. BMJ 1997;315:629-34.

25 Sutton AJ, Duval SJ, Tweedie RL, Abrams KR, Jones DR. Empirical assessment of effect of publication bias on meta-analyses. BMJ 2000;320:1574-7

26 Bax L, Yu LM, Ikeda N, Tsuruta H, Moons KG. Development and validation of MIX: comprehensive free software for meta-analysis of causal research data. BMC Med Res Methodol 2006;6:50.

27 World Health Organization. The world health report 2002-reducing risks promoting healthy life. WHO, 2002.

28 Scientific Advisory Committee on Nutrition. Salt and health. Stationery Office, 2003:1-134.
29 World Health Organization. Reducing salt intake in populations. Report of a WHO forum and technical meeting. WHO, 2007:1-60.

30 Lewington S, Clarke R, Qizilbash N, Peto R, Collins R. Age-specific relevance of usual blood pressure to vascular mortality: a metaanalysis of individual data for one million adults in 61 prospective studies. Lancet 2002;360:1903-13.

31 Karppanen H, Mervaala E. Sodium intake and mortality. Lancet 1998;351:1509.

32 Kupari M, Koskinen P, Virolainen J. Correlates of left ventricular mass in a population sample aged 36 to 37 years. Focus on lifestyle and salt intake. Circulation 1994;89:1041-50.

33 Schmieder RE, Messerli FH, Garavaglia GE, Nunez BD. Dietary salt intake. A determinant of cardiac involvement in essential hypertension. Circulation 1988;78:951-6.

34 Du Calair G, Ribstein J, Daures JP, Mimran A. Sodium and left ventricular mass in untreated hypertensive and normotensive subjects. Am J Physiol 1992;263:H177-81.

35 Avolio AP, Clyde KM, Beard TC, Cooke HM, Ho KK, O’Rourke MF. Improved arterial distensibility in normotensive subjects on a low salt diet. Arteriosclerosis 1986;6:166-9.

36 Du Calair G, Ribstein J, Mimran A. Dietary sodium and target organ damage in essential hypertension. Am J Hypertens 2002;15:222-9.

37 Verhave JC, Hillege HL, Burgerhof JG, Janssen WM, Gansevoort RT, Navis GJ, et al. Sodium intake affects urinary albumin excretion especially in overweight subjects. J Intern Med 2004;256:324-30.

38 National Institutes of Health. Clinical guidelines on the identification, evaluation, and treatment of overweight and obesity in adults- the evidence report. Obes Res 1998;(suppl 2):51-209S.

39 Strazzullo P, Barba G, Cappuccio FP, Siani A, Trevisan M, Farinaro E, et al. Altered renal sodium handling in men with abdominal adiposity and insulin resistance: a link to hypertension. J Hypertens 2001;19:2157-64.

40 World Health Organization. The world health report 2004-changing history. WHO, 2004.

41 Selmer RM, Kristiansen IS, Haglerod A, Graff-Iversen S, Larson HK, Meyer $\mathrm{HE}$, et al. Cost and health consequences of reducing the population intake of salt. J Epidemiol Community Health 2000;54:697-702.

42 Murray CJ, Lauer JA, Hutubessy RC, Niessen L, Tomijima N, Rodgers A, et al. Effectiveness and costs of interventions to lower systolic blood pressure and cholesterol: a global and regional analysis on reduction of cardiovascular-disease risk. Lancet 2003;361:717-25.

43 Asaria P, Chisholm D, Mathers C, Ezzati M, Beaglehole R. Chronic disease prevention: health effects and financial costs of strategies to reduce salt intake and control tobacco use. Lancet 2007;370:2044-53.

44 Godlee F. The food industry fights for salt. BMJ 1996;312:1239-40.

45 Cappuccio FP. Salt and cardiovascular disease. BMJ 2007;334:859-60.

Accepted: 22 October 2009 